\title{
Left ventricular systolic time intervals in patients with acute myocardial infarction
}

\author{
B J NORTHOVER
}

From the Leicester Royal Infirmary, Leicester

SUMMARY Left ventricular systolic time intervals were measured daily during 601 episodes of acute myocardial infarction. The ratio of pre-ejection period to ejection period during the first 24 hours permitted patients to be arranged in six prognostic groups with mortalities while in hospital ranging from 4 to 60 per cent. The only factors completely independent of the systolic time intervals which were shown statistically to be associated with high mortality while in hospital were defects in atrioventricular and intraventricular conduction.

Various prognostic scoring schemes have been devised for patients who have sustained an acute myocardial infarction. Those of Peel and coworkers, ${ }^{1}$ of Killip and Kimball, ${ }^{2}$ and of Norris and co-workers ${ }^{3}$ are still widely used. Items of information which have been derived both subjectively and objectively are often incorporated in such scores. In terms of morbidity and mortality, however, the short-term prognosis is determined almost solely by the extent of the damaged myocardium. ${ }^{4-11}$ The damaged tissue may contain areas of necrosis, both old and new, plus areas of muscle which, though still viable, contract feebly. Hori and co-workers ${ }^{12}$ showed that the total volume of injured tissue was inversely related to certain measures of the pumping effectiveness of the heart. Indeed, a reliable prognostic score may be derived solely from appropriate measurements of the pumping effectiveness of the heart. ${ }^{13-21}$ Ideally, such measurements should be obtainable non-invasively. Systolic time intervals provide a convenient non-invasive method for assessing left ventricular pumping effectiveness. ${ }^{22}$ As would be expected, therefore, the short-term prognosis of patients with acute myocardial infarction correlates with their systolic time intervals. $^{23-33}$ Reservations have been expressed, however, concerning the accuracy of the systolic time intervals in measuring the pumping effectiveness of the heart in patients with acute myocardial infarction, and hence of their prognostic significance. ${ }^{34-40}$ The present study is an attempt to refine the techniques of recording and measuring systolic time intervals so that a more reliable prognosis can Received for publication 12 November 1979 be made in patients with acute myocardial infarction, particularly in relation to their mortality while in hospital.

\section{Subjects and methods}

Patients admitted to the Leicester Royal Infirmary who fulfilled the World Health Organization criteria ${ }^{41}$ for a "definite acute myocardial infarction" were studied prospectively. A total of 601 distinct episodes of acute myocardial infarction during 596 separate admissions in $\mathbf{5 7 8}$ persons form the basis of this report. The majority of these people had sought attention in a public accident department on account of retrosternal discomfort, which was still present in 86 per cent on arrival at the hospital. The author visited the wards at least once and usually twice each day to examine every patient suspected on clinical grounds of having an acute myocardial infarction. Inevitably, a few patients were accidentally overlooked and a few died so soon after admission that electrocardiographic and biochemical evidence needed to secure the diagnosis was not obtained. A few patients with a proven acute myocardial infarction died before being seen by the author. The total of all these exclusions is estimated to constitute approximately 2 per cent of the total of acute myocardial infarctions in patients who were alive on arrival at the hospital during the period of this study. A standard 12 lead electrocardiogram was recorded on admission and routinely on a daily basis for the first few days in hospital and whenever a change of cardiac rhythm was noted by the ward staff. Patients were connected 
to bedside electrocardiograph oscilloscope monitors for approximately the first three days in hospital. All disturbances of cardiac rhythm recorded electrocardiographically were classified by the author using the criteria of Schamroth. ${ }^{42}$ Venous blood was analysed for creatine kinase, aspartate aminotransferase, and hydroxybutyrate dehydrogenase on a daily basis for approximately the first three days in hospital. Serum concentrations of creatine kinase and at least one of the other two enzymes were required to be above the upper limit of the locally defined normal range in at least one blood sample to qualify for the World Health Organization description" of "elevated serum enzymes". Rises in serum creatine kinase were not accepted as evidence of acute myocardial infarction in patients with clinical evidence of recent injury to brain or skeletal muscle, or who had received electrical cardioversion, or who had convulsed in the preceding four days, or who were myxoedematous by biochemical criteria.

Most patients received an oxygen enriched atmosphere to breathe for the first 24 hours. This was delivered via plastic nasal prongs. Initial pain relief was provided with diamorphine administered parenterally. Nausea was relieved as far as possible with the aid of prochlorperazine administered parenterally. Left ventricular failure was treated initially and mainly with frusemide given intravenously, followed later, if required, by frusemide or a thiazide diuretic given orally. Few received digoxin for this purpose. Heparin was administered subcutaneously and prophylactically to an increasing proportion of the patients as the period of this study continued. Antiarrhythmic drugs were not administered routinely on a prophylactic basis. Ventricular extrasystolic activity of sufficient severity to cause concern to the ward staff was usually treated with lignocaine, 2 or $3 \mathrm{mg} / \mathrm{min}$, intravenously. In the few patients where this was ineffective, alternative agents such as mexiletine or disopyramide were used. Digoxin was administered orally to patients with atrial fibrillation. Few patients received beta-receptor blocking agents while in hospital, and these were mainly persons who had received them previously for angina or arterial hypertension. Pericarditic pain was usually treated with a short course of indomethacin given orally. Other complications and concomitant diseases occurred so infrequently or were managed in so many different ways that it is not possible to make generalisations about treatment.

The majority of patients were nursed on acute medical wards, but a few were managed for all or part of their time on other wards including one with facilities for positive pressure ventilation.
During the period of this study no specially designated coronary care unit existed in the hospital. Because of various degrees of atrioventricular block and the expected need for electrical pacing, or because of a need for cardiac catheterisation, 15 patients were transferred to other hospitals. The fate of these patients after transfer is included in this report. Patients were deemed to have survived if they were discharged to their own home or to a local convalescent home. The overall survival rate was 84 per cent and the average duration of hospital stay of survivors was 13 days. The non-survivors lived for an average of three days from onset of symptoms.

RECORDING OF SYSTOLIC TIME INTERVALS As soon as possible after admission of the patient to the ward (referred to as day 1), left ventricular systolic time intervals were measured by the author from a simultaneous recording of an electrocardiogram, a phonocardiogram, and a carotid pulse trace, recorded strictly according to the recommendations of Weissler. ${ }^{22}$ The median time interval between the onset of persistent chest discomfort and the first recording of systolic time interval was 12 hours, approximately four hours of which was the result of delay in getting to hospital and a further three hours in getting to the ward. All traces were made at a paper speed of $100 \mathrm{~mm} / \mathrm{s}$ on an ultraviolet recorder of type M19UV made by Devices of Welwyn Garden City, Hertfordshire. An electrocardiographic lead showing a $Q$ wave was selected. The phonocardiogram was recorded in most patients from the third intercostal space at the left sternal edge, using a microphone of type MSC-IT, made by Nihonkohden of Tokyo, Japan, which was attached to the chest wall with a rubber strap. The output from the microphone was led to an amplifier of type 3545 made by Devices and adjusted to respond maximally in the range 6 to $10 \times 10^{2} \mathrm{~Hz}$, with attenuation below this range. The amplifier was adjusted to delineate clearly the aortic (first) component of the second heart sound (A2). The recording position and frequency responsive range sometimes needed to be modified slightly in patients with a systolic murmur or rub. The carotid pulse trace was recorded by placing a hand-held hollow hemispherical plastic cup (diameter $2 \mathrm{~cm}$ ) against the side of the neck directly over the right common carotid artery, just medial to the sternocleidomastoid muscle. In a few patients with absent right carotid pulsation the recording was made from the left side. The cup was connected via a $6 \mathrm{~cm}$ length of air-filled thick-walled plastic tubing (internal diameter $4 \mathrm{~mm}$ ) to a pressure transducer of type 4-327-L221, made by Bell \& Howell of Basingstoke, 
Hampshire. The output from the transducer was led via an amplifier of type 3552 to another of type 3551 (both made by Devices) adjusted to give an undamped response below $30 \mathrm{~Hz}$. The time constant of the whole assembly was in excess of five seconds, and there was no frequency-dependent phase shift detectable below $10^{2} \mathrm{~Hz}$. The carotid pulse trace was adjusted to approximately $12 \mathrm{~cm}$ amplitude in all patients, including those with feeble pulses. All recordings were obtained with the patients' legs supported horizontally on a bed and with the head and upper trunk at approximately $45^{\circ}$ to the horizontal. Recordings were made once each day, with the patient breathing spontaneously.

CALCULATION OF SYSTOLIC TIME INTERVAL Left ventricular systole begins with the $Q$ wave of the electrocardiogram and ends with the $\mathrm{A} 2$ sound (the QA2 interval). The left ventricular ejection period (EP) was the time from the beginning of the upstroke of the carotid pulse trace to its incisura. The pre-ejection period (PEP) was calculated as follows:

$$
\mathrm{PEP}=\mathrm{QA2}-\mathrm{EP}
$$

Unlike the PEP and the EP separately, the ratio $\mathrm{PEP} / \mathrm{EP}$ is independent of heart rate. ${ }^{22}$

At least 20 consecutive heart beats were averaged to obtain a representative value of $\mathrm{PEP} / \mathrm{EP}$ in patients with atrial fibrillation. A mean of at least 10 heart beats (as far as possible consecutive beats uninterrupted by extrasystoles or dropped beats) during two to four complete respiratory cycles was measured in other patients. Any recorded extrasystoles were ignored when calculating systolic time intervals, as were heart beats immediately after extrasytoles, on account of postextrasystolic potentiation. Patients with QRS complexes showing a left bundle-branch block pattern have a large and variable prolongation of the pre-ejection period. In addition, the first component of their second heart sound does not coincide with aortic valve closure. In this study, therefore, patients with this abnormality did not have systolic time intervals measured. In a few patients with a stable ectopic pacemaker apparently in the left ventricle the systolic time intervals were measured in the usual way. There were no patients with a stable ectopic pacemaker apparently located in the right ventricle on admission, though this developed while in hospital in one patient, at which time systolic time interval measurements were discontinued.

\section{Results}

Preliminary studies showed that the mean value of PEP/EP among 170 patients of both sexes in hospital who were between 30 and 70 years and were without evidence of any cardiovascular disease was $\mathbf{0 . 2 8} \pm$ SE $\mathbf{0 . 0 3}$. Patients with acute myocardial infarction who displayed unequivocal evidence of left ventricular failure as judged by physical examination (classes 3 and 4 of Killip and Kimball ${ }^{2}$ ) almost invariably (98\%) showed a value of PEP/EP in excess of $0 \cdot 33$. Most of these patients showed both an abnormally prolonged pre-ejection period and an abnormally shortened ejection period as judged from the heart rate-adjusted values quoted by Weissler. ${ }^{22}$ In a minority (16\%) of this group, however, the high value of PEP/EP was the result of an isolated abnormality in either the numerator or the denominator. The PEP/EP ratio seems to be more reliable than either of its components, therefore, in detecting moderate and severe left ventricular failure. For this reason the ratio was adopted as the routine measure of left ventricular pumping effectiveness in the present study.

The PEP/EP ratio showed a characteristic rise and subsequent fall in most patients during the first few days after the onset of acute myocardial infarction (Fig.). The extent of the rise in PEP/EP and its timing showed little correlation with survival. In contrast, the magnitude of the first recorded value of PEP/EP was closely correlated with the subsequent mortality in hospital. For the remainder of this report, therefore, patients are arranged in six prognostic groups depending upon their PEP/EP value on day 1 (Table 1). Groups 1 and 2 combined contained 64 per cent of the

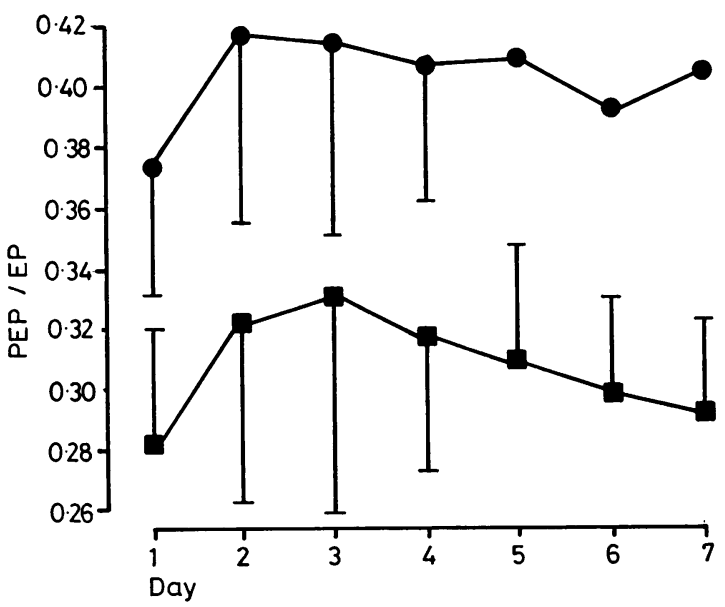

Fig. Daily mean PEP/EP values in survivors (squares) and in eventual non-survivors (circles). Vertical bars represent $S D$ of mean. There were 476 eventual survivors and 86 eventual non-survivors on day 1. The number of eventual non-survivors declined thereafter. By day 5 there were too few eventual non-survivors to permit a meaningful calculation of $S D$ of mean. 
Table 1 Numbers of patients showing various features, arranged according to PEP/EP value on day 1

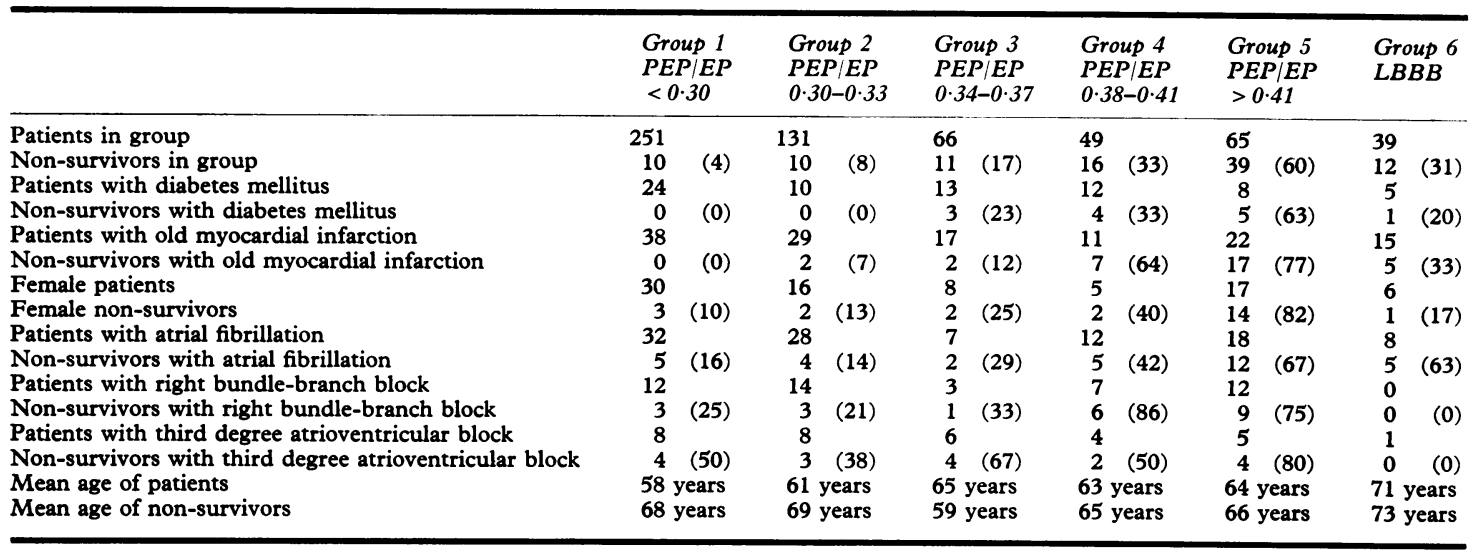

Figures in parentheses represent the non-survivors as a percentage of the patients showing a particular feature within the group.

patients and showed a mortality of only 5 per cent. Groups 3 to 5 contained fewer patients but a progressively higher mortality ( $\chi^{2}$ test, $\mathrm{p}<0.00001$ ). Group 6 consisted of patients with left bundlebranch block on admission, who also showed a substantial mortality while in hospital.

In 11 per cent of patients with acute myocardial infarction, despite having no clinical evidence of cardiac failure (belonging to class 1 of Killip and $\mathrm{Kimball}^{2}$ ), the PEP/EP value on day 1 was greater than 0.33 . The mortality of these patients while in hospital was 14 per cent, which is approximately treble that of patients with a PEP/EP value on day 1 of 0.33 or less. Some, but not all, of these patients with apparently subclinical cardiac failure had received narcotic analgesic or diuretic drugs before the measurement of the systolic time interval, which may account in part for their lack of physical signs. Basal lung crepitations (cardiac failure class 2 of Killip and Kimball) ${ }^{2}$, on the other hand, were heard by the author on day 1 in 21 per cent of patients when the PEP/EP recorded at the same time was less than 0.30 . Such patients showed a mortality in hospital which was no greater than that of patients with a complete absence of evidence of cardiac failure. These observations suggest that the classical clinical signs of mild left ventricular failure are less successful than systolic time intervals in assessing the prognosis of these patients.

Previous workers have noted a statistical association between the mortality of patients with acute myocardial infarction and certain features such as their age and sex or the coexistence of other morbid conditions such as diabetes mellitus or a previous myocardial infarction. Abnormalities of cardiac rhythm such as atrial fibrillation, right bundle- branch block, or third degree atrioventricular block also have been reported to be associated with poor short-term survival. ${ }^{1}$ The frequency with which these features were noted in groups 1 to 6 together with the associated mortalities is shown in Table 1.

The members of group 6 were significantly older than the other patients in the study, and the survivors in group 1 were significantly younger than the other patients (in both cases $p<0.01$, using Student's $t$ test). There was no statistically significant difference between the ages of the other groups of patients or between the ages of the other survivors and non-survivors. Thus, age had only a small impact upon short-term survival in the present study.

Sufficient numbers of patients to permit a useful statistical analysis by means of the $x^{2}$ test were obtainable only by combining some of the groups. Thus, Tables 2 and 3 have been constructed with groups 1 and 2 combined on the one hand, and with groups 3 to 6 combined on the other hand. Table 2 shows that diabetes mellitus, myocardial infarction, right bundle-branch block, and third degree atrioventricular block were more frequent among groups 3 to 6 than among groups 1 and 2 . Except in the case of the female sex and third degree atrioventricular block these differences reached an acceptable level of statistical significance. Table 3 shows the impact of these features upon short-term mortality. In contrast to the findings of some previous investigators the presence or absence of diabetes mellitus was associated with no significant difference in mortality. In contrast, a previous myocardial infarction or female sex were both associated with a greater mortality than where these features were absent. The difference in 
Table 2 Percentage prevalence of various features among patients arranged according to the $P E P / E P$ value on day 1

\begin{tabular}{|c|c|c|c|c|}
\hline & $\begin{array}{l}\text { All groups } \\
\text { combined }\end{array}$ & $\begin{array}{l}\text { Groups } 1 \text { and } \\
2 \text { combined } \\
(P E P / E P \\
<0.34)\end{array}$ & $\begin{array}{l}\text { Groups } 3 \text { to } \\
6 \text { combined } \\
\text { (PEP/EP } \\
>0.33 \text { plus } \\
\text { LBBB })\end{array}$ & $p^{\star}$ \\
\hline $\begin{array}{l}\text { Patients with } \\
\text { diabetes mellitus }\end{array}$ & 12 & 9 & 17 & 0.0060 \\
\hline $\begin{array}{l}\text { Patients with old } \\
\text { myocardial } \\
\text { infarction }\end{array}$ & & & & \\
\hline $\begin{array}{l}\text { 1nfarction } \\
\text { Female patients }\end{array}$ & $\begin{array}{l}22 \\
14\end{array}$ & $\begin{array}{l}18 \\
12\end{array}$ & $\begin{array}{l}30 \\
16\end{array}$ & 0.1505 \\
\hline $\begin{array}{l}\text { Patients with atrial } \\
\text { fibrillation }\end{array}$ & & & & \\
\hline $\begin{array}{l}\text { fibrillation } \\
\text { Patients with right }\end{array}$ & 18 & 16 & 25 & 0.0061 \\
\hline $\begin{array}{l}\text { bundle-branch } \\
\text { block } \\
\text { Patients with third }\end{array}$ & 8 & 7 & 13 & 0.0100 \\
\hline ventricular block & 5 & 4 & 7 & $0 \cdot 1556$ \\
\hline
\end{tabular}

* $p$ represents the probability, assessed by the $\chi^{2}$ test, that the difference in prevalence of the listed feature between members of groups 1 and 2 combined and members of groups 3, 4, 5, and 6 combined could have occurred by chance.

mortality was statistically significant among members of groups 3 to 6 combined but not among members of groups 1 and 2 combined. In the case of atrial fibrillation the position was reversed, with a significantly higher mortality among the fibrillating as opposed to the non-fibrillating members of groups 1 and 2 combined, but not among the members of groups 3 to 6 combined. Patients showing right bundle-branch block or third degree atrioventricular block showed a distinct and consistently higher mortality than was found among those in whom these features were absent. The differences in mortality were statistically highly significant not only for members of groups 1 and 2 combined but also for the members of the other groups combined. Both right bundle-branch block and third degree atrioventricular block constitute, therefore, mortality risk factors which are fully independent of the pumping effectiveness of the left ventricle.

Too few patients with third degree atrioventricular block were provided with transvenous right ventricular electrical pacing to permit any conclusions regarding the effectiveness of this treatment in preventing death. Thus, nine patients were paced, of whom five died, whereas there were 12 deaths among the 23 non-paced patients. While in hospital, left bundle-branch block developed in 14 patients, of whom four died. This is a similarly high mortality to that shown by patients with left bundle-branch block on admission (group 6), and it is significantly higher than the overall mortality of patients in this study. Members of groups 3, 4, and 5 combined developed left bundle-branch block while in hospital significantly more frequently than the combined members of groups 1 and 2 . This is consistent with the previous observations of Biddle and co-workers. ${ }^{43}$

Table 3 Mortality percentages among patients grouped according to the PEP/EP value on day 1

\begin{tabular}{|c|c|c|c|c|c|c|}
\hline & $\begin{array}{l}\text { Groups } 1 \text { and } 2 \\
\text { combined }\end{array}$ & $p^{\star}$ & $\begin{array}{l}\text { Groups } 3 \text { to } 6 \\
\text { combined }\end{array}$ & $p^{\star}$ & $\begin{array}{l}\text { All groups } \\
\text { combined }\end{array}$ & $p^{\star}$ \\
\hline Patients with diabetes mellitus & 0 & \multirow[b]{2}{*}{$0 \cdot 2993$} & 35 & \multirow[b]{2}{*}{0.8856} & 18 & \multirow[b]{2}{*}{$0 \cdot 7523$} \\
\hline Patients without diabetes mellitus & 6 & & 36 & & 16 & \\
\hline Patients with old myocardial infarction & 3 & \multirow{2}{*}{0.5179} & 48 & \multirow{2}{*}{0.0213} & 25 & \multirow{2}{*}{0.0040} \\
\hline Patients without old myocardial infarction & 6 & & 30 & & 14 & \\
\hline Female patients & 11 & \multirow{2}{*}{$0 \cdot 1296$} & 53 & \multirow{2}{*}{0.0289} & 30 & \multirow{2}{*}{0.0009} \\
\hline Male patients & 5 & & 32 & & 14 & \\
\hline Patients with atrial fibrillation & 15 & \multirow[t]{2}{*}{0.0006} & 46 & \multirow[t]{2}{*}{$0 \cdot 1037$} & 30 & \multirow[t]{2}{*}{$<0.0001$} \\
\hline Patients without atrial fibrillation & 3 & & 32 & & 13 & \\
\hline Patients with right bundle-branch block & 24 & \multirow[t]{2}{*}{$<0.0001$} & 62 & \multirow[t]{2}{*}{0.0026} & 44 & \multirow[t]{2}{*}{$<0.0001$} \\
\hline Patients without right bundle-branch block & 4 & & 31 & & 14 & \\
\hline $\begin{array}{l}\text { Patients with third degree atrioventricular } \\
\text { block }\end{array}$ & 44 & \multirow[t]{2}{*}{$<0.0001$} & 69 & \multirow[t]{2}{*}{0.0088} & 56 & \multirow[t]{2}{*}{$<0.0001$} \\
\hline $\begin{array}{l}\text { Patients without third degree } \\
\text { atrioventricular block }\end{array}$ & 4 & & 33 & & 14 & \\
\hline
\end{tabular}

* $p$ represents the probability, assessed by the $\chi^{2}$ test, that the difference in mortality between patients with and without the listed feature could have occurred by chance. 


\section{Discussion}

The present study indicates that the short-term survival of patients in hospital with acute myocardial infarction may be predicted with considerable accuracy solely from a knowledge of the pumping effectiveness of the left ventricle as judged by the PEP/EP ratio measured on the first day. In general, this confirms the findings of previous workers (see introduction). Weissler ${ }^{22}$ has pointed out, however, that systolic time interval measurements depend to some extent upon the value of cardiac preload and afterload, both of which represent largely uncontrolled variables in patients with acute myocardial infarction. This source of variability has been invoked as an explanation by several previous workers who failed to obtain acceptable prognostic accuracy from systolic time interval measurements (see introduction). In the present study, however, the prognostic accuracy attained was similar to that derived from measurements of cardiac pumping effectiveness based upon cardiac catheterisation, a technique which permits an allowance to be made for the prevailing conditions of cardiac preload and afterload. ${ }^{21}$ Alternative explanations for the limited success of previous attempts at a prognosis based upon systolic time intervals are worthy, therefore, of consideration. In the author's opinion the most important factor in reliable systolic time interval measurement is strict adherence to the recommendations of Weissler. ${ }^{22}$ The scanty details of recording and measuring technique in some previous reports of systolic time intervals in patients with acute myocardial infarction suggest that the importance of these aspects of methodology has not been appreciated by some investigators. Subsidiary and probably minor reasons for the greater prognostic success obtained in the present study compared with previous attempts may be the greater number of patients in the present work plus the fact that all recordings and measurements were performed by one operator. The usefulness of systolic time intervals in routine clinical practice, therefore, may be limited by the need to standardise so carefully the recording and measuring techniques. A large and uncontrollable variable in the present study was the variety of treatment which the patients received before and during hospitalisation. This may represent a limitation to greater prognostic precision. Efforts were made in the present study to analyse possible statistical associations between the treatment received by patients and subsequent events in hospital, both in terms of survival and in terms of systolic time interval values. Unfortunately, nothing of statistical significance emerged despite the fact that previous workers have demonstrated profound effects of these drugs on systolic time interval values. This failure is probably accounted for in part by the varied doses and times of administration of the drugs in relation to the measurements of systolic time intervals in the present study. It should be noted in this connection that the only value of PEP/EP which had prognostic significance was the first measurement. This measurement was made at an early stage, when most of the patients had already received diamorphine and prochlorperazine, but few had received any other treatment. Perhaps greater scatter and lack of prognostic significance of later measurements of PEP/EP are a result of the confounding influence of the varied forms of treatment which the patients received increasingly as time progressed in hospital.

In any survey of a disease it is necessary to consider the extent to which the cases presented are typical of the condition as it exists in the community. An element of selection is inevitable in any study which is hospital-based. Nevertheless, the patients in the present study have been consecutive admissions to a district general hospital, largely via a public accident department. The patients probably represent a wide spectrum of the disease. The converse may apply where a selective admissions policy operates. A feature which should be emphasised in this connection is that the average patient on entry to the present study had already survived the first 12 hours of the disease. During this early phase, particularly the prehospital period, there is a substantial mortality. It would be interesting to know whether these early deaths may be predicted from the measurement of systolic time intervals. This information, however, will be difficult to obtain.

Many of the features of patients with acute myocardial infarction which have been shown by previous investigators to be associated with a poor prognosis have been found to occur more frequently in patients with poor rather than with good left ventricular pumping effectiveness in the present study. The pathophysiological mechanisms which account for these associations are largely unknown and merit further investigation. Prior myocardial infarction or female sex were associated with increased mortality among groups 3 to 6 combined but not among groups 1 and 2 combined. This suggests that the mortality risk associated with these features depends upon the prevailing pumping effectiveness of the left ventricle, but this does not seem to have been noticed previously. Failure to take account of this factor may explain some of the conflicting reports on this subject which have been published. The situation with right bundle-branch block and third degree atrioventricular block was 
simpler, since both features seemed to constitute statistically significant mortality risk factors which were independent of the level of left ventricular pumping effectiveness. Previous workers have pointed out that these defects in the spread of the cardiac action potential were associated with a high mortality in patients with acute myocardial infarction. ${ }^{4-50}$ Again, the available evidence does not permit conclusions regarding the pathophysiological mechanisms responsible for the increased mortality. This merits further investigation, as does the question of whether or not electrical pacing or pharmacological interventions would improve the survival of these patients.

The author acknowledges the co-operation of many members of the staff of the Leicester Royal Infirmary, in particular the encouragement of $\mathrm{Dr}$ J R Hearnshaw.

\section{References}

'Peel AAF, Semple T, Wang I, Lancaster WM, Dall JLG. A coronary prognostic index for grading the severity of infarction. Br Heart $\mathcal{f} 1962 ; 24$ : 745-60.

${ }^{2} \mathrm{Killip}$ T, Kimball JT. Treatment of myocardial infarction in a coronary care unit; a two year experience with 250 patients. Am $\mathcal{F}$ Cardiol 1967; 20: 457-64.

${ }^{3}$ Norris RM, Brandt PWT, Caughey DE, Lee AJ, Scott PJ. A new coronary prognostic index. Lancet 1969; 1 : 274-8.

¿Sobel BE, Bresnahan GF, Shell WE, Yoder RD. Estimation of infarct size in man and its relation to prognosis. Circulation 1972; 46: 640-8.

${ }^{5}$ Kostuk WJ, Ehsani AA, Karliner JS, et al. Left ventricular performance after myocardial infarction assessed by radioisotope angiography. Circulation 1973; 47: 242-9.

${ }^{6}$ Mathey D, Bleifeld W, Hanrath P, Effert S. Attempt to quantitate relation between cardiac function and infarct size in acute myocardial infarction. $\mathrm{Br}$ Heart $\mathfrak{f}$ 1974; 36: 271-9.

'Roberts R, Hussain A, Ambos HD, Oliver CG, Cox JR Jr, Sobel BE. Relation between infarct size and ventricular arrhythmia. Br Heart $\mathcal{f} 1975$; 37: 1169-75.

${ }^{8}$ Ahumada G, Roberts R, Sobel BE. Evaluation of myocardial infarction with enzymatic indices. Prog Cardiovasc Dis 1976; 8: 405-20.

'Bleifeld WH, Hanrath P, Mathey D. Serial CPK determinations for evaluation of size and development of acute myocardial infarction. Circulation 1976; 53 and 54, suppl I: 108-11.

${ }^{10}$ Cox JR Jr, Roberts R, Ambos HD, Oliver GC, Sobel BE. Relations between enzymatically estimated myocardial infarct size and early ventricular dysrhythmia. Circulation 1976; 53 and 54, suppl I: 150-5.

${ }^{11}$ Fukui S. Quantitative assessment of myocardial infarct size from serial determinations of serum creatine phosphokinase activity. $\mathcal{F a p}$ Cir $\mathcal{F} 1977$; 41 : 837-46.
${ }^{12}$ Hori $M$, Fukui $S$, Inoue $M$. Infarct size and left ventricular ejection fraction in acute myocardial infarction (in Japanese). Fap Circ F 1977; 41 : 1299-306.

${ }^{13}$ Corya BC, Rasmussen S, Knoebel SB, Feigenbaum H. Echocardiography in acute myocardial infarction. $A m \mathcal{F}$ Cardiol 1975; 36: 1-10.

${ }^{14}$ Schulze RA Jr, Rouleau J, Rigo P, Bowers S, Strauss HW, Pitt B. Ventricular arrhythmias in the late hospital phase of acute myocardial infarction. Relation to left ventricular function detected by gated cardiac blood pool scanning. Circulation 1975; 52: 1006-11.

${ }^{15}$ DeMaria AN, Angel J, Amsterdam EA, Mason DT. Accurate assessment of extent and prognosis in acute myocardial infarction by echographic index of ejection fraction and ventricular volume; close correlation with cardiac catheterization determined stroke work (abstract). Am f Cardiol 1976; 37: 131.

${ }^{16}$ DeMaria AN, Angel J, Amsterdam EA, et al. Applications of echocardiography in acute myocardial infarction: development of a prognostic index and estimation of left ventricular filling pressure. In: Mason DT, ed. Advances in heart disease. vol 1. New York: Grune \& Stratton, 1977: 367-76.

${ }^{17}$ DeMaria AN, Angel J, Newmann A, Lee G, Amsterdam EA, Mason DT. Non-invasive echocardiographic index for determining prognosis in acute myocardial infarction. Adv Cardiol 1978; 22: 65-70.

${ }^{18}$ Schelbert HR, Henning H, Ashburn WL, Verba JW, Karliner JS, O'Rourke RA. Serial measurements of left ventricular ejection fraction by radionuclide angiography early and late after myocardial infarction. Am $\mathfrak{f}$ Cardiol 1976; 38: 407-15.

${ }^{19}$ Kitchen AH, Pocock SJ. Prognosis of patients with acute myocardial infarction admitted to a coronary care unit. I. Survival in hospital. Br Heart $\mathcal{f}$ 1977; 39: 1163-6.

${ }^{20}$ Lorente $\mathrm{P}$, Delabre $\mathrm{M}$. Use of correspondence analysis in processing haemodynamic data from acute myocardial infarction. Comput Biomed Res 1977; 10: 213-35.

${ }^{21}$ Weber KT, Janicki JS, Russell RO, Rackley CE. Identification of high risk subsets of acute myocardial infarction. Am $\mathcal{F}$ Cardiol 1978; 41: 197-203.

${ }^{22}$ Weissler AM. Non-invasive cardiology. New York: Grune \& Stratton, 1974.

${ }^{23}$ Wayne HH. Serial apexcardiograms, phonocardiograms and carotid tracings in myocardial infarction (abstract). Circulation 1968; 37 and 38, suppl VI: 203.

${ }^{24}$ Toutouzas P, Gupta D, Samson R, Shillingford J. Q-second sound interval in acute myocardial infarction. Br Heart $\mathcal{F} 1969$; 31 : 462-7.

${ }^{25}$ Diamant B, Killip $T$. Indirect assessment of left ventricular performance in acute myocardial infarction. Circulation 1970; 42: 579-92.

${ }^{26}$ Rufty AJ, Ramo BW, Wallace AG, Whalen RE, McIntosh HD, Clark DO. Correlation of left ventricular ejection time with stroke index in patients with acute myocardial infarction. Ann Intern Med 1970; 70: 780 .

${ }^{27}$ Samson $\mathbf{R}$. Changes in systolic time intervals in acute myocardial infarction. Br Heart f 1970; 32: 839-46.

${ }^{28}$ Gould L, Michael AH, Gomprecht RF. The systolic 
time intervals in myocardial infarction. Angiology 1971; 22: 568-74.

${ }^{29}$ Heikkilä J, Luomanmäki K, Pyörälä K. Serial observations on left ventricular dysfunction in acute myocardial infarction. II. Systolic time intervals in power failure. Circulation 1971; 44: 343-54.

${ }^{30}$ Jain SR, Lindahl J. Apex cardiogram and systolic time intervals in acute myocardial infarction. Br Heart $\mathcal{f}$ 1971; 33: 578-84.

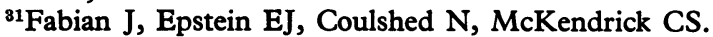
Duration of phases of left ventricular systole using indirect methods. II. Acute myocardial infarction. $\mathrm{Br}$ Heart $\mathcal{F} 1972$; 34: 882-9.

${ }^{32}$ Brubakk O, Overskeid K. Systolic time intervals in acute myocardial infarction. Acta Med Scand 1976; 199: $33-40$.

${ }^{33} \mathrm{Nishi} \mathrm{K}$. Evaluation of left ventricular function in acute and old myocardial infarction by non-invasive method with special reference to systolic time intervals. fap Circ F 1976; 40: 427-34.

${ }^{34}$ Dowling JT, Sloman G, Urquart C. Systolic time interval fluctuations produced by acute myocardial infarction. Br Heart $\mathcal{F}$ 1971; 33: 765-72.

${ }^{35}$ Hamosh P, Cohn JN, Engelman K, Broder MI, Freis ED. Systolic time intervals and left ventricular function in acute myocardial infarction. Circulation 1972; 45: 375-81.

${ }^{36}$ Hodges M, Halpern BL, Friesinger GC, Dagenais GR. Left ventricular pre-ejection period and ejection time in patients with acute myocardial infarction. Circulation 1972; 45: 933-42.

${ }^{37}$ Loeb H, Rahimtoola SH, Sinno MZ, Lal R, Rosen K, Gunnar R. Failure of systolic time intervals to reflect changes in stroke volume following plasma volume expansion in acute myocardial infarction (abstract). Circulation 1972; 45 and 46, suppl II: 184.

${ }^{38}$ Loeb HS, Rahimtoola SH, Rosen KM, Sinno MZ, Chuquimia R, Gunnar RM. Assessment of ventricular function after acute myocardial infarction by plasma volume expansion. Circulation 1973; 47: 720-8.

${ }^{39}$ Perloff JK, Reichek N. Value and limitations of systolic time intervals (preejection period and ejection time) in patients with acute myocardial infarction. Circulation 1972; 45: 929-32.
${ }^{40}$ Gunnar RM, Loeb HS, Rahimtoola SH. Left ventricular function in patients with acute myocardial infarction. In: Gunnar RM, Loeb HS, Rahimtoola $\mathrm{SH}$, eds. Shock in myocardial infarction. New York: Grune \& Stratton, 1974: 65-84.

${ }^{41}$ World Health Organization. Regional Office for Europe. Ischaemic heart disease registers: report of the fourth working group. Copenhagen: the Organization, 1970.

${ }^{42}$ Schamroth L. The disorders of cardiac rhythm. Oxford: Blackwell Scientific Publications, 1971.

${ }^{43}$ Biddle TL, Ehrich DA, Yu PN, Hodges M. Relation of heart block and left ventricular dysfunction in acute myocardial infarction. Am 7 Cardiol 1977; 39: 961-6.

${ }^{44}$ Julian DG, Vellani CW, Godman MJ, Terry G. Prolongation of QRS duration in acute myocardial infarction. Prog Cardiovasc Dis July 1970; 13: 56-71.

${ }^{45} \mathrm{Lim} \mathrm{CH}$, Toh CCS, Low LP. Atrioventricular and associated intraventricular conduction disturbances in acute myocardial infarction. $B r$ Heart $\mathcal{f} 1971 ; 33$ : 947-54.

${ }^{46}$ Atkins JM, Leshin SJ, Blomqvist G, Mullins CB. Ventricular conduction blocks and sudden death in acute myocardial infarction. $N$ Engl f Med 1973; 288: 281-4.

${ }^{4}$ Lie KI, Wellens HJ, Schuilenburg RM, Becker AE, Durrer D. Factors influencing prognosis of bundle branch block complicating acute anteroseptal infarction. Circulation 1974; 50: 935-41.

${ }^{48}$ Norris RM, Mercer CJ. Significance of idioventricular rhythm in acute myocardial infarction. Prog Cardiovasc Dis 1974; 16: 455-68.

${ }^{49} \mathrm{Jones}$ ME, Terry G, Kenmure ACF. Frequency and significance of conduction defects in acute myocardial infarction. Am Heart f 1977; 94: 163-7.

${ }^{50}$ Otterstad JE, Gundersen S, Anderssen N. Left anterior hemiblock in acute myocardial infarction. Acta Med Scand 1978; 203: 529-34.

Requests for reprints to Dr B J Northover, Coronary Care Unit, Leicester Royal Infirmary, Leicester LE1 5WW. 